International Journal of Social Science And Human Research

ISSN(print): 2644-0679, ISSN(online): 2644-0695

Volume 05 Issue 02 February 2022

DOI: 10.47191/ijsshr/v5-i2-07, Impact factor-5.586

Page No: 426-431

\title{
Experiences of Patients with Bipolar Disorder in a Psychoeducational Group: A Qualitative Study
}

\author{
Raúl Hormazábal-Salgado ${ }^{1}$, Margarita Poblete-Troncoso ${ }^{2}$ \\ ${ }^{1}$ Universidad de Talca, Avenida Lircay sin número, Talca, Chile. \\ ${ }^{2}$ Universidad Católica del Maule, Avenida San Miguel 3605, Talca, Chile.
}

\begin{abstract}
:
Background: Bipolar disorder contributes to high rates of morbidity with serious consequences on the quality of life. There is limited research on life experience of people with this mental disorder in educational interventions, in Chile.

Objective: The aim of this study was to examine the experiences of patients with a diagnosis of bipolar disorder who participated in a psychoeducational programme in a regional hospital.

Methodology: The methodological approach used was qualitative descriptive. The participants were selected until the theoretical saturation of the information was reached. Information was collected through semi-structured interviews.

Results: The psychoeducational group experience favours learning and acceptance of the disease. The interviewees reported seeing themselves reflected in other participants, feeling welcomed within the group, wanting to help and establishing close relationships with other participants. Confidence on mental healthcare providers and their role in educating about the disease and pharmacological treatment were emphasized.
\end{abstract}

Conclusion: Psychoeducational group experience is significant for the interviewees and helps them manage their disease.

KEYWORDS: Bipolar Disorder; Bipolar Mood Disorder; Health Education; Mental Health; Mental Health Nursing

\section{BACKGROUND}

Bipolar disorder, classically known as "Manic-Depressive Psychosis", is a severe, chronic and recurrent mental illness; it is a major source of morbidity and mortality with serious consequences for the quality of life. [1] Bipolar disorder implies a high risk of relapse, associated with its chronicity or chronic course, recurrence and a high prevalence of non-adherence to treatment. [2, 3] This is relevant since in Chile there is a higher prevalence of the disorder than in Latin America and the Caribbean. [4, 5] Therefore, specialised interventions such as psychoeducation must be implemented in order to enhance the quality of life of people. Psychoeducation is a procedure carried out in groups of patients, who receive a thorough instruction about their illness, enabling them to manage the associated individual and social complications of bipolar disorder, providing valuable tools that allow them to live with their illness in a better way. [2]

Mental health nursing is crucial to help people with mental illnesses through an integrative approach; however, this speciality has remained fixed in an intermediate conception of its history, influenced by the psychopathological orientation of psychiatric services, in detriment to nursing care and thus patient's autonomy. [6] Barros et al. argue that there should be a health-centred approach rather than an illness-centred approach that allows for a broadening of the possibilities for action. [7] Psychoeducation for people with bipolar disorder arises as a person-centred intervention, improving significantly the quality of care for this population. It is essential to know the experiences of those affected by bipolar disorder who participate in a psychoeducational programme in order to identify their main beliefs and concerns, thus improving nursing care in this area. However, there is little research that would allow to reach a better understanding of the subject.

For all the above reasons, the present study was conducted in order to find out the experience of people with bipolar disorder who participated in a psychoeducational intervention.

The guiding questions formulated to orientate this research were the following:

-What has been the experience of users, carriers of bipolar disorder, when participating in the psychoeducational group?

-What is the most important knowledge acquired during the educational intervention, in terms of managing their illness? 


\section{Experiences of Patients with Bipolar Disorder in a Psychoeducational Group: A Qualitative Study}

\section{METHODOLOGY}

This study used the descriptive qualitative approach, which emphasises the individual experience of users and the meaning that they attach to it. [8] In addition, the following quality criteria were considered: Credibility, Assurance, Reliability or auditability and Confirmability. [9] The study was carried out in the outpatient psychiatric unit of a regional hospital in Chile.

The psychoeducational groups were formed with an average total of 15 users. A brief psychoeducational programme of eight sessions was given to users with bipolar affective illness, lasting for about two months. The main topics were creating awareness of the illness, encouraging adherence to medication, early detection of new episodes, maintaining regularity in habits and stress management. The average dropout rate at the last group session for all groups was around $70 \%$ (five users). The professionals involved in the group sessions were a nurse, a psychiatrist and a psychologist. The nurse and psychologist were in all the eight group sessions, whereas the psychiatrist was only present in the session focused on the topic of pharmacotherapy.

This study was conducted between the years 2013 and 2014. In order to carry out the present study, the rights of people with mental disabilities were considered, which involve respect for autonomy, through the voluntary nature of participation; beneficence and justice, as an equitable improvement in their care is sought; and non-maleficence, by ensuring that risks are minimised through confidentiality. These ethical aspects were safeguarded through the informed consent of the study participants and the evaluation of the study by the scientific ethics committee from the Maule Health Service.

The inclusion criteria were the following: users with diagnosed bipolar affective disorder, aged between 18 and 65 years, who can read, write and in treatment in the public health network belonging to this Regional Hospital, referred by treating physicians. The medical criterion allows the selection of those users who are compensated, with preserved judgement of reality and in full exercise of their autonomy. Due to the characteristics of the group work and of the present research, users were excluded if they had relapses in a current bipolar episode, psychiatric or personality disorders whose severity significantly limits or contraindicates their group work, moderate-severe cognitive impairment, antisocial personality disorder, severe hearing loss and having attended less than five sessions of the psychoeducational group.

The collection of information was carried out by means of semi-structured interviews, once the eight sessions of group psychoeducation were over, and was characterised by allowing the free expression of the users. The interviews were carried out by the researcher himself, in a private box for his exclusive use; they were recorded, in order to include the entire discourse and to avoid omissions of information. They were carried out until the theoretical saturation of information was reached, [10] with a total of seven interviewees.

The data were analysed through thematic analysis, [11] extracting categories and units of meaning. Firstly, the interviews were transcribed and then read in order to obtain a general idea of the information. Secondly, codes were assigned to the interviews to preserve the privacy of the interviewees while maintaining their fidelity. After that, the analysis was carried out in every line, sentence, and paragraph, from which the units of meaning were obtained and understood as examples that initially support the concepts and develop the meanings. Finally, similar codes were grouped, constructing the themes, thus reducing or summarising the data.

A process of triangulation of information was conducted according to Cisternas. [12] This consists of triangulation between different disciplines, where an expert opinion of a member of the health team who has not been involved in the research is requested, in order to verify whether the guiding questions have been answered; and triangulation with the theoretical framework, where relevant literature on the topic has been addressed. Additionally, a participant checking or verification [13] was carried out, where the participants read the transcripts of their own interview, in order to ensure credibility.

\section{RESULTS}

The main results were grouped in four categories: Positive perception of the group, group experience as learning about the disease, the role of the health team in the group, and the experience of catharsis within the group.

\section{A. Positive perception of the Group}

The perceptions of the interviewees tend to be favourable:

"I felt so good, welcomed and I think all of us, not only me, felt so welcomed, it was our desired space." (Interviewee 3, female)

"You realise, as you go through the course, that people feel touched in their innermost self with respect to the course, with respect to what is being dealt with.... (Interviewee 5, male)

In the context of group interactions, the desire to help emerges: 


\section{Experiences of Patients with Bipolar Disorder in a Psychoeducational Group: A Qualitative Study}

"I recognised that I was falling into alcoholism (...) I thought that this was the instance to tell it, because maybe it could happen to one of those in the group, so I wanted to help them." (Interviewee 3, female)

Some patients talked about the friendship with other participants in the group:

"Friendship with people who also went to the workshops is very important, it has done me a lot of good." (Interviewee 6, female)

"I made friends, and we have continued to get together, they are very good friends of mine." (Interviewee 7, female)

\section{B. Group experience as learning about the disease}

Learning corresponds to a central theme that emerges in the discourses emitted by all interviewees, and includes several topics.

One interviewee talks about the learning she achieved thanks to the group experience:

"I learnt about concerns that I had about my disease because I got the knowledge, for several aspects of it." (Interviewee 2, female)

Knowing about the disease is addressed as an important issue:

"When you know what is wrong with you, you know how to deal with it; on the other hand, if you don't know something, you don't know how to attack it or try to lessen it." (Interviewee 3, female)

Knowing about pharmacotherapy was also a topic of great importance:

"There were a lot of concerns about the medicines, the properties they had." (Interviewee 2, female)

"I was medicated because medical doctors gave me certain medicines, but the truth is that I never knew clearly what each of them were going to do for me." (Interviewee 3, female)

"It was never clear to me that the medicines were for good until I went to the groups." (Interviewee 7, female)

One interviewee expressed her shock at learning of the chronic nature of the illness she suffers from:

"I came to know now that I had this illness, so-called bipolarity. When I went to the groups, I found out that the illness was forever (...) that the remedies are forever." (Interviewee 7, female)

\section{The role of the health team in the group}

All the participants described the role of the professionals who conformed the team in charge of the group:

"The psychologist had a set of "magic" words, it was like she had a magic wand that she would use to touch those who were concerned the most, and as soon as she touched them from far away, they got quiet and relaxed, feeling super good and listened." (Interviewee 1, female)

"As a doctor goes to the workshop for an hour, you have enough time to ask him any questions about the disease, so it is easier when the doctor is at the workshops than when you go to the doctor yourself; since I only go to the doctor a couple of times a year, I have no time left to ask him questions there...." (Interviewee 6, female)

"The nurses were excellent, always concerned for all the people in the group, not for someone in particular, but for all of them equally." (Interviewee 2, female)

"I think that everyone responded with respect to what the group sessions were intended to; the healthcare team was good, they shed a lot of light on the subject, because we were able to clarify certain questions." (Interviewee 5, male)

\section{The experience of catharsis withing the group}

The unfavourable personal perceptions correspond mostly to catharsis, which refers to certain phenomena of massive emergence of unconscious feelings, facilitated by regression. [14] In other words, during group interaction, a large number of users evoke and express multiple feelings of which they were not fully aware.

Interviewees explained the situations of catharsis they witnessed from others during the group sessions:

"There was one of the members of the group, and it was like the whole meeting was only for her and she was talking and repeating herself, over and over again, and I thought to myself: why is she here instead of going to individual therapy?" (Interviewee 1, female)

"I find catharsis very hard for everyone, because once I came out of a group session feeling in a very bad mood, and I found out that for the people who were talking about their painful experiences it was tremendous." (Interviewee 4, female) 


\section{Experiences of Patients with Bipolar Disorder in a Psychoeducational Group: A Qualitative Study}

\section{DISCUSSIONS}

This qualitative descriptive study describes the experiences of participants patients in a psychoeducational intervention tailored to their needs in terms of managing their disease.

The users agreed in feeling welcomed during their participation in the psychoeducational group, as pointed out by the interviewees. Feeling welcomed means feeling safe, making them confident enough to exchange experiences with other participants. The conversations about the main topics for each session lead people to tell others about their life experiences with the disease, including their own personal struggles. One patient described her desire to help others that led her to share her experience of alcohol consumption, in order to warn about the risks of that behaviour. In this case, the client disclosed her alcohol use after recognising that the presence of such behaviour as a coping strategy was seriously harming her. Feeling welcomed and understood motivated participants to open up and share their experiences, being this one of the main aspects of mental health support groups, offering a path to self-enhancement and collective empowerment. [15]

The bonds of friendship between users that emerged from the group experience, were described as positive and significant. Such bonds have formed spontaneously between users who share the same mental disease (bipolar disorder) and related difficulties. Maintaining continuity in these relationships was perceived as a functional support network that has transcended the group intervention and allows them to cope better with the disease by supporting each other. Consequently, fostering friendship ties between users is a way of favouring their empowerment in terms of healthcare as well as socialization and support. [16]

Learning in psychoeducational groups was experienced as a process by the interviewees. Several aspects were a motive of great concern for the participants, namely: bipolar disorder itself, medication, and its chronic nature. The uncertainty of not knowing the role of each drug in the symptomatologic control of the disease is a recurrent concern in the lives of those affected. Medication intake must be performed on a daily basis in order to control the symptoms of the disease, deeply influencing their lives. According to Kartalova-O'Doherty \& Doherty, [17] medication is perceived as helpful at the beginning of treatment and during relapses, but over-medication or their side effects can be detrimental for the person. Therefore, knowing about both therapeutic and side effects of medication throughout the course of the mental disease is crucial for the individuals. Likewise, the acceptance of the inherent chronic nature of bipolar disorder is relevant. One of the participants described her interpretation of the chronic course of the disease by referring "it is forever," because she was told by her psychiatrist that she needed to always adhere to the medical treatment. Consequently, the chronic course exerts a significant impact of the patient's life. It is particularly striking that the situation described above occurs despite the fact that several interviewees have reported years of following the prescribed medical treatments. For this reason, it is imperative to tackle any knowledge gap regarding treatment, because in the process of adherence behaviour, the patients' perceptions are the central tenet; by consequence, future research should examine and aim to understand these patient related factors. [18]

The patients also reported that having achieved significant knowledge about bipolar disorder, allows them to have more perceived control over it. The perceived relevance of knowing one's own illness is a basis for an adequate symptomatologic control. Avoiding episodes of decompensation is directly related to the identification of the so-called prodromal symptoms of bipolar disorder, defined as several indicators that precede acute illness. [19] The basis for early detection is to act proactively by managing these prodromal symptoms, avoiding crises and thereby gaining control over the illness. In this aspect, the role of psychoeducational group interventions provides tools for a better management of bipolar disorder. By implication, using the knowledge acquired was seen as a necessary step for the control of the illness by applying it to everyday life.

The role of the healthcare team was highlighted for all the interviewees. The three team members together, the psychologist, the nurse and the psychiatrist, were important for complying with the main goals in the psychoeducational intervention. The psychologist was described as an expert in terms of allowing patients to express themselves within the group, helping them to calm down in the immediate aftermath of their intervention. Similarly, the participation of the psychiatrist, although was limited to only one out of the eight sessions, was crucial for the patients because he helped them understand the relevance of medication to control their disease. Nurses were perceived as impartial, in terms of assisting all people equally in the group while leading the sessions. This recognition of every patient as a unique individual could ultimately lead to their independence, moving away from the predominant dichotomous asylum-era thinking of mental illness towards positive health aims by improving the capacity of individuals and communities to make their own decisions; mental health nurses are the catalysts for these processes. [20]

The spontaneous occurrence of catharsis in groups is described as a factor that is unfavourable to the fluidity of interactions, leading to feelings of rejection towards group participation. Experiences of catharsis in the group users was facilitated by the fact of feeling in a safe environment, supported by the health team and other users. In general terms, catharsis is considered a positive and desirable phenomenon in group therapy, as it allows feelings to be expressed and then worked on. [21] However, psychoeducational group intervention lacks the necessary resources to carry out a therapeutic approach (mainly due to time 


\section{Experiences of Patients with Bipolar Disorder in a Psychoeducational Group: A Qualitative Study}

constraints), in addition to the negative consequences that catharsis has on the other participants. Consequently, the objectives of therapy were incompatible with those of the psychoeducational group experience developed in this setting.

\section{LIMITATIONS}

This study is not exempt of a number of limitations. Only seven people were interviewed for the purposes of this study. The participants were chosen by convenience since their availability determined the order of the interviews. The themes identified were specific to these seven participants and may not apply in other settings. Only one participant out of seven interviewed was male while the rest were female. The participants were over 40 years old, so younger people were not included. The interviewer was the same nurse who managed the educational groups so his active role in this study as the main researcher may carry a bias, in terms of not being able to obtain accurate information from the participants. The data analysis was conducted through an interpretive process, meaning that other interpretations of the data are possible. The data were collected about eight years before publishing this article. However, the situation explored has remained almost unchanged and unexplored in Chile. Therefore, it is relevant to disseminate these findings considering the scarcity of studies in educational interventions for people with bipolar disorder.

\section{CONCLUSIONS}

The findings of this study are in line with the literature in terms of improving the quality of mental healthcare. The experience of patients during their participation in the group was overall positive, because they felt welcomed and understood while creating bonds of friendship with other participants, thus broadening their social support networks. In addition, learning includes not only knowledge about bipolar disorder and pharmacotherapy but also management strategies of prodromal symptoms, favouring the acceptance of bipolar disorder, its chronic course and ultimately, adherence to treatment. To achieve this, teamwork within the professionals that lead the intervention is imperative for a successful outcome. Negative group experiences are directly related to catharsis, an undesired event that deviates from the group objectives, deteriorating the quality of the interventions. Thereby, it is the role of the healthcare team to prevent these events by setting boundaries during the sessions, while providing one-by-one opportunities for certain patients to express their concerns individually and privately to the healthcare professionals, whenever necessary.

From this experience, we make a series of suggestions for clinical practice in mental health. Considering the positive perceptions from the participants, establishing a continuous functioning of psychoeducational groups and replicating the experience focused on patients with other mental disorders and/or their families is highly encouraged. The role of mental health nurses in prevention is key to manage healthcare by following an integrative approach, in concordance with community healthcare, since this is the modern model of mental health services worldwide. Future research should be focused on the effectiveness of group psychoeducation in users with bipolar disorder by means of a different methodology and/or different settings, besides finding out the reasons why some patients abstain from participating and/or leaving the psychoeducational group. Factors that could play a role in treatment adherence might be extensively explored due to their relevance. All of this could help to enhance mental health services for people living with bipolar disorder and their families.

\section{ACKNOWLEDGMENT}

The authors would like to express their gratitude to those who participated in the research for sharing their stories.

\section{REFERENCES}

1) Colom, F. \& Vieta, E. (2004). Manual de psicoeducación para el trastorno bipolar. Barcelona: Ars Medica.

2) Ivanovicic, F., Valdebenito, C., Lolas, F. (2007). Psicoeducación en pacientes con trastorno bipolar. Aspectos bioéticos. Psiquiatría.com. Available from: http://www.psiquiatria.com/revistas/index.php/psiquiatriacom/article/download/245/230

3) Pardo, E., Fierro, M., Ibáñez PM. (2011). Prevalencia y factores asociados a la no adherencia en el tratamiento farmacológico de mantenimiento en adultos con trastorno afectivo bipolar. Universidad del Rosario; Available from: http://repository.urosario.edu.co/bitstream /10336/2398/1/47434947\%5b1\%5d.pdf

4) Kohn, R., Levav, I., Almeida, J. M. C. de, Vicente, B., Andrade, L., Caraveo-Anduaga, J. J., Saxena, S., \& Saraceno, B. (2005). Los trastornos mentales en América Latina y el Caribe: asunto prioritario para la salud pública. Revista Panamericana de Salud Publica [Pan American Journal of Public Health], 18(4-5), 229-240. https://doi.org/10.1590/s1020-49892005000900002

5) Vicente, B., Kohn, R., Rioseco, P., Saldivia, S., Baker, C., \& Torres, S. (2004). Population prevalence of psychiatric disorders in Chile: 6-month and 1-month rates. The British Journal of Psychiatry: The Journal of Mental Science, 184, 299-305. https://doi.org/10.1192/bjp.184.4.299

6) Lavorato Neto, G., Rodrigues, L., Silva, D. A. R. da, Turato, E. R., \& Campos, C. J. G. (2018). Spirituality review on mental health and psychiatric nursing. Revista Brasileira de Enfermagem, 71(suppl 5), 2323-2333. 


\section{Experiences of Patients with Bipolar Disorder in a Psychoeducational Group: A Qualitative Study}

https://doi.org/10.1590/0034-7167-2016-0429

7) Barros, S., Oliveira, M. A. F. de, \& Silva, A. L. A. e. (2007). Práticas inovadoras para o cuidado em saúde. Revista Da Escola de Enfermagem Da U S P, 41(spe), 815-819. https://doi.org/10.1590/s0080-62342007000500013

8) Rodríguez, G, Gil, J, García, E. (1996). Metodología de la Investigación Cualitativa. Ediciones Aljibe; Granada.

9) de Gialdino, I. V. (2007). Estrategias de Investigacion Cualitativa. Gedisa Editorial.

10) Saunders, B., Sim, J., Kingstone, T., Baker, S., Waterfield, J., Bartlam, B., Burroughs, H., \& Jinks, C. (2018). Saturation in qualitative research: exploring its conceptualization and operationalization. Quality \& quantity, 52(4), $1893-1907$. https://doi.org/10.1007/s11135-017-0574-8

11) Crowe, M., Inder, M. \& Porter, R. (2015). Conducting qualitative research in mental health: thematic and content analyses. Australian and New Zealand Journal of Psychiatry, 49, 616-623.

12) Cisterna, F. (2005). Categorización y triangulación como procesos de validación del conocimiento en investigación cualitativa. Theoría. Volumen 14 No 1.

13) Creswell J.W. Qualitative inquiry and research design: Choosing among five approaches. Segunda edición. Estados Unidos: Sage Publications; 2007.

14) Palomo, T. \& Jiménez-Arriero, M.A. (2009). Manual de Psiquiatría. Madrid: Ene Life Publicidad S.A. y Editores.

15) Crabtree, J. W., Haslam, S. A., Postmes, T., \& Haslam, C. (2010). Mental health support groups, stigma, and self-esteem: Positive and negative implications of group identification: Mental health and stigma. The Journal of Social Issues, 66(3), 553-569. https://doi.org/10.1111/j.1540-4560.2010.01662.x

16) Van Metre, L; Chiappetta, L; Siedel, B; Fan, T; Mitchell, A. M. (2011). Educating for Wellness: A Wellness Education Group Intervention for Adults with Chronic Severe Mental Illness Living in the Community. Issues in Mental Health Nursing, 32(7), 408-415. doi:10.3109/01612840.2011.553771

17) Kartalova-O'Doherty, Y.; Doherty, D. T. (2011). Recovering from mental health problems: Perceived positive and negative effects of medication on reconnecting with life. International Journal of Social Psychiatry, 57(6), 610-618. doi:10.1177/0020764010377396

18) Chakrabarti S. (2014). What's in a name? Compliance, adherence and concordance in chronic psychiatric disorders. World journal of psychiatry, 4(2), 30-36. https://doi.org/10.5498/wjp.v4.i2.30

19) Larson, M. K., Walker, E. F., \& Compton, M. T. (2010). Early signs, diagnosis and therapeutics of the prodromal phase of schizophrenia and related psychotic disorders. Expert review of neurotherapeutics, 10(8), 1347-1359. https://doi.org/10.1586/ern.10.93

20) Wand, T. (2013). Positioning mental health nursing practice within a positive health paradigm. International Journal of Mental Health Nursing, 22(2), 116-124. doi:10.1111/j.1447-0349.2012.00848.x

21) Lefevor, G. T., \& Williams, J. S. (2021). An interpersonally based, process-oriented framework for group therapy with LGBTQ clients. In Violence Against LGBTQ+ Persons (pp. 347-359). Springer International Publishing. Attribution - Non Commercial 4.0 International (CC BY-NC 4.0) (https://creativecommons.org/licenses/by-nc/4.0/), which permits remixing, adapting and building upon the work for non-commercial use, provided the original work is properly cited. 